\title{
Educação Permanente em Saúde e Governamentalidade Biopolítica: uma Análise Genealógica
}

Permanent Education in Healthcare and Biopolitic Governmentality: a Genealogical Analysis Educación Permanente en Salud y Gubernamentabilidad Biopolítica: una Análisis Genealógica

\section{Gisele Santin}

Universidade de Santa Cruz do Sul, Santa Cruz do Sul, RS, Brasil.

\section{Betina Hillesheim}

Universidade de Santa Cruz do Sul, Santa Cruz do Sul, RS, Brasil.

\section{Resumo}

Este trabalho apresenta uma análise genealógica da formação em saúde no Brasil, enfatizando o campo de forças que permitiu a constituição da estratégia de Educação Permanente em Saúde enquanto política pública orientadora da formação e ordenação dos recursos humanos para a área da saúde. O exercício genealógico analisa as condições de possibilidade para a emergência da referida estratégia, buscando compreender algumas das rupturas que permitiram a legitimação de determinados discursos sobre saúde no Brasil, mediante a produção de verdades. Assim, o presente artigo apresenta algumas condições históricas que possibilitaram a constituição da Educação Permanente em Saúde, discutindo os jogos de verdade que a produzem e são produzidos pela mesma e seus efeitos sobre a formação dos trabalhadores da saúde. Para isso, utilizam-se como ferramentas de análise os conceitos de biopolítica, governamentalidade, regimes de verdade.

Palavras-chave: Educação permanente em saúde; Biopolítica; Governamentalidade; Genealogia

\begin{abstract}
This work presents a genealogical analysis of the degree in healthcare in Brazil, emphasizing the force field that has allowed the constitution of the estrategy Permanent Education in Healthcare as a guiding public policy of the formation and ordination of the human resources to the healthcare area. The genealogic exercise analyzes the conditions of possibility to the emergence of the policy referred, seeking to understand some of ruptures that have permitted the legitimation of certain speeches about health in Brazil, by the means of production of truth. Thus, this article presents some historic conditions that have enabled the constitution of the Permanent Education
\end{abstract}


in Healthcare, discussing the truth games which produce it and are produced by it and its effects on the education of healthcare workers. Thereunto, the concepts of biopolitics, governmentality, and regimes of truth are used as tools of analysis.

Key words: Permanent education in healthcare; Biopolitics; Governmentality; Genealogy

\section{Resumen}

Este trabajo presenta uma analisis genealógica de la formación en Salud en Brasil, enfatizando el campo de fuerzas que permitió la constitución de la estrategia Educación Permanente en Salud en cuanto, política pública orientadora de la formación y ordenación de los recursos humanos para el área de la salud. El ejercicio genealógico analiza las condiciones de posibilidades que permitirán la legitimación de determinados discursos sobre salud en Brasil, mediante la producción de verdades. Así, el presente artigo presenta algunas condiciones históricas que posibilitaron la constitución de la Educación Permanente en Salud, discutiendo los juegos de verdad que la producen y son producidos por la misma y sus efectos sobre la formación de los trabajadores de la salud. Para eso, se utiliza como herramienta de análisis los conceptos de biopolítica, gubernabiliadad, regímenes de verdad.

Palabras llaves: Educación permanente en Salud; Biopolítica; Gubernabiliad; Genealogía

A formação profissional em saúde é um tema debatido desde o processo da reforma sanitária brasileira que culminou com a criação do Sistema Único de Saúde (SUS) em 1988, tanto que, na Lei Orgânica da Saúde (Lei 8.080/90), já está posto que a formação e a ordenação dos recursos humanos da área da saúde cabem ao SUS. Nesse sentido, o tema tem sido pauta de discussão em espaços diversos, sendo que, principalmente na última década, houve muitas iniciativas por parte de gestores, instituições de ensino, movimento estudantil e dos próprios trabalhadores, em busca de uma for- mação profissional em saúde comprometida com a integralidade da atenção. Assim, através da Portaria $N^{\circ}$ 198/GM/MS de 13 de fevereiro de 2004, o Ministério da Saúde instituiu a Política Nacional de Educação Permanente em Saúde (Brasil, 2004a), a qual tem os objetivos de organizar uma política de formação e desenvolvimento para os profissionais da saúde em todos os níveis educacionais e, especialmente, dar ênfase à formação em serviço e à mudança de perfis subjetivos dos trabalhadores.

A Educação Permanente em Saúde, como estratégia para mudanças na forma- 
ção, constituiu-se ao longo do processo da Reforma Sanitária Brasileira e da construção da Saúde Coletiva durante a década de 1980, sendo difundida pela Organização Pan-Americana de Saúde (OPAS), com o objetivo de alcançar o desenvolvimento dos sistemas de saúde (Ceccim, 2005). Seu corpo teórico e conceitual foi concebido com a influência da Educação Popular, do Movimento Institucionalista e também de experiências concretas desenvolvidas por trabalhadores da saúde (Ceccim, 2005). Um dos diferenciais da Educação Permanente em Saúde em relação às propostas de formação tradicional é a abordagem da formação e gestão do trabalho em saúde, não como “questões simplesmente técnicas, já que envolvem mudanças nas relações, nos processos, nos atos de saúde e, principalmente, nas pessoas (Brasil, 2004b, p. 11). Ou seja, o foco do investimento não é o aprimoramento técnico, mas sim a subjetividade do trabalhador.

Deste modo, é preciso considerar que, ao tomar o trabalhador de saúde como foco de uma política pública, o Estado busca conduzir condutas, ou seja, insere-se na problemática do que Foucault (2008) nomeia como governamentalidade. Fimyar (2009), citando Lemke, pontua que esse neologismo criado por Foucault, a partir da fusão de governar e mentalidade, pretende dar visibilidade à estreita relação entre as práticas de governamento e as mentalidades que as sustentam. Assim, conforme Foucault (2003), as práticas de governo se relacionam com a noção de um governo econômico, isto é, operar de modo que se produza o máximo de riquezas possíveis, fornecendo às pessoas o máximo de substâncias possíveis, de maneira que todo o corpo social seja passível de se tornar objeto de governamento.

Partindo do pressuposto de que as políticas públicas, além de se constituírem em respostas às demandas sociais, também podem ser consideradas como estratégias de regulamentação do corpo social e de governo das condutas, ou seja, de relações de poder, é importante destacar as mudanças nos mecanismos de poder, entendendo, a partir de Foucault, o poder na sua positividade. Conforme Foucault (2005), a partir da época clássica, o ocidente passou por uma transformação profunda nos mecanismos de poder, onde o interesse começou a ser o reforço, a incitação, a majoração de forças, "um poder destinado a produzir forças, a fazê-las crescer e a ordená-las mais do que a barrá-las, dobrá-las ou destruí-las" (p. 128). Este poder sobre a vida se desenvolveu a partir do século XVII, mediante duas maneiras que não são opostas, mas interligadas: a anatomopolítica do corpo humano, caracterizada pelos mecanismos disciplinares e centrada no corpo como máquina, no 
seu adestramento e na ampliação e extorsão das suas forças; e a biopolítica das populações, que se desenvolveu um pouco mais tarde, na metade do século XVIII, visando à gestão da vida e fazendo aparecer, nas práticas políticas e econômicas, os problemas de natalidade, saúde pública, habitação, entre outros (Foucault, 2005).

A biopolítica traz em seu bojo a ideia de governar os vivos mediante o controle dos fenômenos inerentes à vida da população e a formas de viver. Este pensamento ajuda a entender o surgimento das políticas públicas de saúde no ocidente a partir do século XIX, pois a nova racionalidade de governo já não agia mais na lógica de "fazer morrer e deixar viver", mas sim, "fazer viver e deixar morrer".

Partindo-se, assim, do entendimento que a construção de um campo de saber não é neutra às relações de poder, este trabalho busca apresentar uma análise genealógica da Educação Permanente em Saúde no Brasil, ou seja, apresentar o campo de forças e as relações de poder que permitiram a constituição desta estratégia de formação profissional em saúde até a sua instituição enquanto política pública. Para tal análise, foram utilizados dois documentos emitidos pelo Ministério da Saúde, denominados Política de educação e desenvolvimento para o SUS: caminhos para a educação permanente em saúde: pólos de educação permanente em saúde, (Brasil, 2004b) e Política Nacional de Educação Permanente em Saúde (Davini, 2009), bem como textos de apoio sobre o tema da formação em saúde. Em relação aos documentos utilizados, salienta-se que sua escolha se deu pela sua relevância na construção da Educação Permanente em Saúde como política pública, sendo que, embora semelhantes, trazem diferentes efeitos para a implementação e organização da mesma.

Além disso, assinala-se que esse exercício genealógico não pretende mostrar uma suposta origem dos fatos, mas sim, as condições de possibilidade para a emergência da Educação Permanente em Saúde, buscando compreender as rupturas e descontinuidades que permitiram a legitimação de determinados discursos sobre saúde no Brasil, mediante a produção de verdades. Na perspectiva genealógica é necessário compreender que "o conhecimento é 'invenção', assim como o sujeito, é uma construção histórica" (Nardi, Tittoni, Giannechini e Ramminger, 2005, p. 1046). Para Foucault (citado por Nardi e Silva, 2005), a questão da verdade está ligada à problemática do governo de si e dos outros, correspondendo à construção de determinadas lógicas que constituem os sujeitos. Dessa maneira, a verdade é produzida por sujeitos livres, inseridos em jo- 
gos de poder. A partir desse entendimento, o presente artigo apresenta algumas das condições históricas que possibilitaram a constituição da Educação Permanente em Saúde, enquanto estratégia de formação dos trabalhadores da área, até a sua instituição como política pública, quando passa a se chamar Política Nacional de Educação Permanente em Saúde, discutindo os jogos de verdade que a produzem e são produzidos pela mesma. Tendo essas questões em vista, analisa-se tal estratégia de formação em saúde, buscando mostrar os jogos de verdade que a sustentam e seus efeitos sobre a formação dos trabalhadores da saúde. Para isto, considera-se, com Foucault (2004), que os discursos são práticas, visto que produzem os objetos de que falam, sendo que a política, ao descrever a formação em saúde que pretende, cria modos de ser trabalhador.

Para isso, utilizam-se como ferramentas de análise os conceitos de biopolítica, governamentalidade, regimes de verdade.

\section{Os jogos de verdade de uma genealogia da formação em saúde}

Na medida em que "não existem origens e nem verdades a desvelar, mas apenas interpretações", pode-se considerar que a genealogia trata da história destas interpre- tações (Nardi e cols., 2005, p. 1047). Assim, Foucault (2004), ao falar sobre o nascimento da medicina moderna no final do século XVIII, já apontava para um modo de trabalho em saúde voltado para a doença, onde a cura dependia de um exato conhecimento da doença e a verdade da vida estava na doença: "o olhar do médico não se dirige inicialmente ao corpo concreto, ao conjunto visível, à plenitude positiva que está diante dele - o doente -, mas a intervalos de natureza, a lacunas e a distâncias em que aparecem como em negativo" (p. 7). Como se discute a seguir, é possível pensar que tal entendimento sobre o trabalho em saúde ecoou também no modelo de formação profissional em saúde.

O ensino formal das profissões em saúde no Brasil iniciou no ano de 1808 com a abertura de duas escolas de medicina e, posteriormente, foram sendo abertas escolas de farmácia, odontologia e enfermagem. Até o Brasil República, era predominante a formação em laboratório: os estudantes aprendiam com profissionais mais experientes, sendo o currículo e método pedagógico autorregulamentados, ou seja, o ensino era livre, sem um currículo mínimo ou diretrizes curriculares nacionais (Carvalho e Ceccim, 2009). Além disso, assim como em outros países, o ensino das profissões da saúde no Brasil foi fortemente influenciado pelo Relatório Flexner. 
O Relatório Flexner, escrito por Abrahan Flexner e publicado em 1910 nos Estados Unidos, teve imensa repercussão no cenário acadêmico. Tal relatório foi produzido em uma época em que o ensino da medicina nos Estados Unidos era caótico, pois não havia necessidade de concessão estatal para o exercício da medicina. Dessa maneira, as escolas eram abertas sem critérios de funcionamento e nem sempre estavam vinculadas às universidades (Pagliosa $\mathrm{e}$ Da Ros, 2008). Dentre as recomendações do Relatório Flexner estão a realização do ensino em laboratórios e hospitais e a separação entre teoria e prática. Tais recomendações apontam para uma formação com ênfase no caráter positivista e biologicista que configurou o regime de verdade sobre a formação em saúde durante os séculos XIX e XX.

No Brasil, a partir da década de 1960 foi observada uma reforma da educação em direção ao ensino da saúde pública e a prevenção em saúde. Um dos fatores importantes para esta mudança foi a atuação da Organização Pan-Americana da Saúde (OPAS) junto às instituições formadoras. Também a definição do conceito de saúde, pela Organização Mundial da Saúde (OMS) como "bem-estar físico, mental e social" apontam para a necessidade do ensino em saúde considerar não apenas as condições biológicas relacionadas à saúde, mas também os fatores emocionais e sociais. A modificação do conceito de saúde indica rupturas no regime de verdade sobre formação em saúde, abrindo-se para outros campos de força.

Foucault (2007) coloca que, na pesquisa genealógica, há uma preocupação não com a busca de uma verdade única, mas com as lutas e combates, ativando saberes locais, descontínuos e considerados como não legítimos. A partir do pensamento do autor, pode-se pensar que a modificação do conceito de saúde relaciona-se a uma mudança de uma racionalidade científica, marcada pelo biologicismo e com status de verdade. Na medida em que ocorre a transformação da noção de saúde, outros saberes, até então minoritários, tornam-se visíveis, insurgindo-se contra um saber hegemônico sobre o que é o cuidado e a formação em saúde, desafiando o discurso médico.

No Brasil, durante a década de 1970 , em plena ditadura militar, foram os projetos de aprendizagem em saúde comunitária que ganharam o debate sobre a mudança na formação em saúde, sendo também um período em que a educação popular foi introduzida como projeto de cidadania (Carvalho e Ceccim, 2009). Conforme Nunes (2009), neste mesmo período floresceram trabalhos teórico-acadêmicos e diversas pesquisas sociais e epidemiológicas que foram dando corpo à medicina social, sendo que a questão da saúde adquire maior visibilidade social, 
sendo alavancada pelos movimentos sociais populares.

Na década de 1980 diversas atividades foram realizadas para a constituição da saúde coletiva, tais como congressos, grupos de trabalhos e pesquisas. Paralelo a isso, emergiam grandes manifestações de trabalhadores da saúde, de associações de bairro e sindicatos que, insatisfeitos com os serviços de saúde, foram dando corpo ao Movimento da Reforma Sanitária que, no ano de 1986, culminou com a VIII Conferência Nacional de Saúde (Nunes, 2009). A VIII Conferência Nacional de Saúde representou um marco para a história das políticas de saúde no Brasil, visto que foi a primeira vez que a população participou das discussões e muitas de suas propostas foram contempladas na Constituição Federal de 1988. Entre elas, o acesso à saúde como direito de todos e dever do Estado e a criação do Sistema Único de Saúde (SUS) (Brasil, 1988).

Os acontecimentos da década de 1980 revelam a efervescência dos movimentos sociais que lutaram pelo fim da ditadura militar e pela redemocratização do país. A sociedade civil organizada, a classe operária, os trabalhadores da saúde e estudantes, entre outros atores sociais, representaram a força micropolítica, mostrando resistência frente ao modelo instituído que se direcionava para as grandes privatizações na área da saúde.
Com a criação do SUS, o Brasil constrói o conceito ampliado de saúde, definido pela Lei Orgânica da Saúde (Lei 8.080/90):

\begin{abstract}
a saúde tem como fatores determinantes e condicionantes, entre outros, a alimentação, a moradia, o saneamento básico, o meio ambiente, o trabalho, a renda, a educação, o transporte, o lazer e o acesso aos bens e serviços essenciais, os níveis de saúde da população expressam a organização social e econômica do país. (Brasil, 1990, s.p.).
\end{abstract}

$\mathrm{Na}$ esteira dos escritos de Foucault (1999) sobre biopolítica, pode-se dizer que tal conceito de saúde aponta para uma transformação nos mecanismos de poder, representando uma espécie de estatização do biológico, no qual a nova tecnologia de poder se dirige à multiplicidade dos homens e aos fenômenos coletivos. Para Bernardes, Morais e Oliveira Junior (2009), a biopolítica representa uma estratégia de poder, cuja racionalidade reside no dever do Estado de regulamentar a vida, ou seja, "uma biorregulamentação pelo Estado" (p. 113), sendo sob essas condições que se torna possível pensar a saúde, por exemplo, como estratégia biopolítica, isto é, como um conjunto de práticas de significação que organizam e regulam a população em seu conjunto. "Assim, a saúde das populações torna-se foco do jogo político, que é um conjunto hetero- 
gêneo operacionalizador de um saber sobre a vida (medicina), um saber sobre o direito (justiça) e um saber sobre a gestão da população (economia política)" (Bernardes e cols., 2009, p. 113).

Nesse sentido, pode-se pensar que as políticas públicas de saúde operam como dispositivos de potência, na medida em que objetivam melhora das condições e qualidade de vida dos sujeitos e, ao mesmo tempo, operam como o que Foucault (2003) denomina como dispositivos de controle das populações através das práticas de governo da vida dentro de um Estado governamentalizado. Para Lemke (citado por Fimyar, 2009, p.38), “(...), a governamentalidade pode ser descrita como o esforço de criar sujeitos governáveis através de várias técnicas desenvolvidas de controle, normalização e moldagem das condutas das pessoas". Entretanto, concomitante a este conceito de governamentalidade como arte de governo, pode-se pensar em um segundo significado para esse termo, o qual se relaciona com o surgimento de novas formas de exercício de poder, que combinam uma nova matriz de racionalidade, a qual reúne uma tecnologia diplomática militar, uma polícia e a redefinição da população como um campo de intervenção.

As politicas públicas de saúde atuam na lógica de uma governamentalidade biopolítica que tem como área de atuação os Rev. Polis e Psique, 2013; 3(2):43-60 fenômenos inerentes à vida da população. Para Foucault, "a biopolítica lida com a população como um problema político, como um problema a um só tempo científico e político, como problema biológico e como problema de poder" (Foucault, 1999, p. 293). Foucault, ao falar sobre o nascimento da medicina social aponta que o capitalismo, desenvolvendo-se em fins do século XVIII e início do século XIX, socializou um primeiro objeto que foi o corpo enquanto força de produção, força de trabalho. O controle da sociedade sobre os indivíduos não se opera simplesmente pela consciência ou pela ideologia, mas começa no corpo, com o corpo. "Foi no biológico, no somático, no corporal que, antes de tudo, investiu a sociedade capitalista. $\mathrm{O}$ corpo é uma realidade biopolítica. A medicina é uma estratégia biopolítica" (Foucault, 2007, p. 47).

Por outro lado, Foucault também elaborou sua concepção de resistência: "lá onde há poder há resistência e, no entanto (ou melhor, por isso mesmo) esta nunca se encontra em posição de exterioridade em relação ao poder" (Foucault, 2005, p. 91). Conforme Bernardes e Quinhones (2009, p. 156), as práticas de governo produzem também o seu avesso: práticas de liberdade. Essas práticas de liberdade não significam um modo de se recusarem as estratégias de governo, mas uma maneira de construção de novos sentidos. As práticas de liberdade, 
nesse caso, são políticas de não escravidão e, para tanto, contemplam também um modelo político. São maneiras de contestação do que é imposto pela cultura, pelas práticas de governo.

Assim, é possível pensar que as políticas públicas não constituem os sujeitos somente como alvo de práticas de governo, mas sim, como sujeitos que governam a si mesmo e que produzem outras formas de existência, "de modo a considerar que o poder não investe apenas em tecnologias de governo do outro, mas em tecnologias de governos de si, forjando figuras existenciais que marcam modos de viver" (Bernardes, 2006, p. 16).

A criação do SUS representa um marco histórico nas políticas de saúde do país, pois além de apontar um novo conceito de saúde, que inclui além dos aspectos biológicos, aspectos sociais e subjetivos da vida da população, também apresenta, a partir dos princípios de universalidade, integralidade e equidade, uma nova relação entre Estado e população: uma relação que não é mais de tutela, mas marcada pela noção de cidadania.

Pode-se compreender que esse embate entre diferentes concepções de saúde passa a constituir o sujeito trabalhador da saúde, sendo que a Educação Permanente em Saúde emerge de um campo de forças que busca garantir a formação para o SUS, visando construir o trabalhador da saúde como ator social, protagonista, autônomo e capaz não apenas de executar, mas de gerir o seu próprio trabalho (Brasil, 2004).

\section{Educação permanente em saúde: novas rupturas}

A Educação Permanente em Saúde articula dois grandes campos de investimento em termos de políticas públicas: a saúde e a educação. Para Soares (2009), a saúde representa hoje uma utopia, pois conquistá-la e preservá-la é um objetivo individual e coletivo a ser alcançado pela população, sendo que, talvez por esse motivo, o Estado não pode ser simplesmente higienista, mas, sobretudo, pedagogo. Dessa forma, para além de pensar a educação permanente como uma estratégia de formação dos trabalhadores da saúde e educação em saúde para a população, também é possível considerá-la em termos de uma prática biopolítica e de governamento.

O processo da Reforma Sanitária e pela consolidação do SUS é atravessado pela questão do trabalho em saúde e pelas discussões em relação à formação e desenvolvimento do trabalhador, temas que compõem o campo de luta do sistema de saúde. Para operacionalizar as ações de educação em saúde, o Ministério da Saúde criou dentro de sua estrutura a Secretaria de Gestão 
do Trabalho e da Educação na Saúde (SGTES) e o Departamento de Gestão da Educação na Saúde (DEGES). A partir de então, assumiu o papel, já definido na legislação, de gestor no SUS em relação "à formulação das políticas orientadoras da formação, desenvolvimento, distribuição, regulação e gestão dos trabalhadores da saúde, no Brasil" (Brasil, 2004b, p. 6). Porém, rever a formação somente durante o ensino superior, técnico e através de capacitações pontuais, não foi considerado suficiente para uma mudança efetiva que pudesse acompanhar a dinamicidade do trabalho em saúde. Desta forma, com o objetivo de unificar os diferentes programas e projetos de formação do pessoal da saúde e torná-los um processo constante, o Ministério da Saúde, instituiu a Política Nacional de Educação Permanente em Saúde, através da Portaria No 198/GM de 13 de fevereiro de 2004 (Brasil, 2004a).

Tal política tem como característica a mudança de estratégia e organização do exercício de formação e de atenção em saúde, visando qualificar o trabalhador para alcançar o cuidado em saúde de acordo com os princípios do SUS e tendo o trabalhador como agente ativo e protagonista nas mudanças pretendidas para seu local de traba1ho. Aqui fica claro outro tipo de agenciamento de produção subjetiva do trabalhador da saúde em relação aos modos anteriores de formação (modelo flexneriano): ao trabaRev. Polis e Psique, 2013; 3(2):43-60 lhador não cabe somente o papel de aplicador de técnicas curativas, mas sim o papel de quem assume uma posição ética e política frente a sua formação e seu trabalho.

Neste ponto, é possível um deslocamento, uma releitura da proposta da Educação Permanente em Saúde. Para além de se configurar em uma política de formação/ produção dos trabalhadores da saúde, ela também vai ao encontro dos objetivos da biopolítica que, a partir do investimento na população, gera a potencialização do Estado. Assim, pode-se vislumbrar a mudança de uma lógica disciplinar na qual o Estado extrai da população somente sua força de trabalho através da docilização dos corpos, para a potencialização da capacidade produtiva e empreendedora do trabalhador da saúde, que também fortalece o Estado. Nesse caso, o Estado investe no trabalhador, o qual otimiza o sistema de saúde situado dentro da política do Estado.

A Educação Permanente em Saúde visa romper com a lógica das capacitações específicas, fragmentadas e direcionadas para profissionais específicos. Isso não significa abolir completamente as capacitações feitas através de cursos sobre temas específicos, mas propor outros modos de trabalhar e de ser trabalhador do/no sistema de saúde. Para Davini (2009), a educação permanente como estratégia sistemática e global, pode abranger ações de capacitações mais pontu- 
ais e específicas desde que estejam articuladas ao processo de mudança institucional.

Como uma vertente pedagógica, a Educação Permanente ganhou estatuto de política pública somente na área da saúde, o que se relaciona ao fato da Organização Pan-Americana de Saúde (OPAS) ter difundido a proposta de Educação Permanente do Pessoal da Saúde com vistas ao desenvolvimento dos sistemas de saúde na América Latina, considerando a complexidade dos serviços de saúde e a aprendizagem significativa como o meio para se conseguir a adesão dos trabalhadores (Ceccim, 2005). Conforme o autor, as principais influências da proposta pedagógica da Educação Permanente em Saúde são: a Educação Popular de Paulo Freire, de onde provém a noção de aprendizagem significativa; o Movimento Institucionalista em Educação de René Lourau e George Lapassade, de onde provém a noção de autoanálise e autogestão; e também os movimentos de mudanças na formação de profissionais da saúde. Davini (2009), aponta que uma corrente de pensamento desenvolvida tanto em experiências concretas como em formulações teóricas, difundidas, principalmente, pela Unesco desde a década de 1970, facilitam o reconhecimento do adulto como sujeito da educação e a ampliação dos espaços de aprendizagem para além da sala de aula, mas ao longo de toda a vida e em contextos comunitários e de trabalho.

Desta forma, é possível dizer que as condições para a emergência da Educação Permanente em Saúde estão colocadas em todo o processo que culminou com a constituição do SUS e não como uma política posterior a ele. Alguns movimentos na América Latina e a sistematização da Educação Permanente pela Organização Pan-Americana de Saúde (OPAS) foram fundamentais para a disseminação deste conceito. A OPAS tem como linha orientadora de trabalho a Educação Permanente em Saúde (EPS) desde o ano de 1984, a qual se desenvolve através do vínculo entre as dimensões do trabalho e educação. "El eje de su preocupación es el trabajador, su labor y su contribución a la atención de salud de la población y la educación permanente de los trabajadores como un instrumento esencial de su desarrollo (Haddad, Roschke e Davini, 1994, p. 34).

Os estudos foucaultianos acerca da biopolítica das populações e da governamentalização do estado nos permitem colocar em suspensão os pressupostos das políticas públicas, pois desnaturalizam seu caráter de evolução e melhoria da ação do estado na sociedade e revelam seu engendramento na lógica da governamentalidade, colocando em pauta seu caráter histórico e político e fazendo ver as relações saber-poder que permitiram seu surgimento. 
A Educação Permanente em Saúde surge também em resposta às demandas dos profissionais da saúde, não sendo uma proposta pensada verticalmente, mas também uma reivindicação dos trabalhadores. Cabe aqui tensionar o que está sendo colocado como autonomia do trabalhador a partir da ideia de capital humano e empreendedor de si, daquele que toma "a si mesmo como seu próprio produtor de rendimentos e de capital” (Duarte, 2009, p. 46). Esta questão não pode ser pensada isoladamente do quadro da racionalidade política que se instalou a partir do liberalismo, como "um sistema preocupado com o respeito aos sujeitos de direito e à liberdade de iniciativa dos indivíduos" (Foucault, 1997, p. 89).

Para Lazzarato (2008), o liberalismo inventa e experimenta diversas técnicas de governo que se exercem sobre o que Foucault chamou de sociedade civil, a qual não é o "espaço onde se fabrica a autonomia em relação ao Estado, mas o correlativo das técnicas de governo" (p. 43). Assim, o Estado e a sociedade civil não atuam em polos opostos, mas a sociedade "faz parte da tecnologia moderna da governamentalidade" (43-44), ou seja, é a partir das reivindicações da sociedade civil que o Estado a incorpora nas suas práticas de governo. Ainda para Lazzarato,

no cruzamento das relações de poder e do que sem cessar lhes escapa, nascem realidades de transação que são de alguma maneira interface entre governantes e governados. É neste cruzamento, na gestão desta interface, que se constitui o liberalismo como arte de governar. É neste cruzamento que nasce a biopolítica (2008, p. 44).

Nas últimas décadas, esta racionalidade de governo vem transformando as relações entre Estado e sociedade, com a passagem do liberalismo para o neoliberalismo. Enquanto que, para o liberalismo, a liberdade de mercado era algo natural, para o neoliberalismo a liberdade é algo a ser produzido continuamente e exercido sob forma de competição (Saraiva e Veiga-Neto, 2009).

A partir do que foi exposto, pode-se perceber que a Educação Permanente em Saúde, constitui-se como uma política de formação profissional em saúde engendrada em mecanismos de poder, entendendo o poder da sua positividade, como produtor de liberdade e desejo, como produtor de sujeitos e subjetividades. No momento em que uma determinada população é investida através de estratégias biopolíticas de governo, também passa a ser constituída e subjetivada por estas estratégias. Ou seja, na medida em que o governo das condutas produz modos de ser, os pressupostos colocados pela Educação Permanente em Saúde constituem determinados sujeitos trabalhadores da saúde e modos de subjetivação. "Nesse espaço criado pela arte de governar encon- 
tram-se as políticas de objetivação-subjetivação que constituem a relação entre Estado e população, ao mesmo tempo em que forjam a relação de sujeitos consigo mesmo" (Bernardes e Hillesheim, 2011, p. 367).

A Educação Permanente em Saúde emerge da constatação de que não é possível relegar a formação a um lugar secundário dentro do sistema de saúde, apenas servindo de retaguarda para a capacitação de recursos humanos; ao contrário, a formação é vista como um dos objetivos finais do sistema de saúde, garantido mediante política pública específica. Como aponta Ceccim, "a introdução desta abordagem retiraria os trabalhadores da condição de 'recursos' para o estatuto de atores sociais das reformas, do trabalho, das lutas pelo direito à saúde e do ordenamento de práticas acolhedoras e resolutivas de gestão e de atenção à saúde" (2005, p 163). Ou ainda como propõe Merhy "coloca no centro do processo pedagógico a implicação ético-política do trabalhador no seu agir em ato, produzindo o cuidado em saúde [...]" (2005, p. 173).

A Educação Permanente em Saúde, muito mais do que romper com modelos tradicionais de formação ao tirar o foco do ensino tecnicista, produz e agencia outros modos de ser trabalhador da saúde, nos quais o investimento não é apenas na qualificação, mas, principalmente, na produção subjetiva dos sujeitos. Desta forma, considera que “a atualização técnico-científica é apenas um dos aspectos da transformação das práticas e não seu foco central. A formação e o desenvolvimento englobam aspectos de produção de subjetividade, de habilidades técnicas e de conhecimento do SUS" (Brasil, 2004b, p. 10). Assim, trabalhadores, estudantes e professores, mediante uma noção de educação permanente, passam a ocupar lugar central nas políticas públicas de saúde, fazendo das práticas de saúde também práticas pedagógicas e compondo outros modos de subjetivação.

\section{Considerações finais}

Este artigo, ao apresentar as rupturas que constituíram a Educação Permanente em Saúde enquanto política de formação dos trabalhadores da saúde, tensionando os jogos de verdade da formação em saúde, busca colocar em evidência que seu surgimento só foi possível em função das rupturas nos modos de poder sobre a vida, onde todo o corpo social é passível de se tornar objeto de governamento, lembrando que "governar não é determinar fisicamente a conduta de objetos passivos. Envolve oferecer razões pelas quais os governados deveriam fazer o que lhes é dito, e isto significa que eles podem também questionar estas razões" (Oksala, 2011 p. 108). 
Na proposta da Educação Permanente em Saúde, é possível vislumbrar esta mudança nos mecanismos de poder: o interesse já não é mais em ter um trabalhador disciplinado e que seu corpo seja uma máquina de realizar tarefas; já não se separa mais o trabalhador dos processos de gestão do trabalho. O trabalhador é colocado como elemento central, visto que o espaço principal de formação é o próprio local de trabalho e as demandas de educação permanente devem acontecer a partir do levantamento das necessidades de formação feito pelos trabalhadores.

A mudança nos mecanismos de poder não significa a ruptura entre eles e, nem mesmo, uma mudança linear. Para Revel (2006), a biopolítica é uma estratégia de proteção e maximização da força de trabalho: a vida do indivíduo vale muito, não em nome de uma filantropia, mas porque ela representa força de trabalho, produção de valor. Dessa forma, "a vida vale porque é útil; mas ela só é útil porque é, ao mesmo tempo, sã e dócil, ou seja, medicalizada e disciplinarizada" (p. 56). A mesma autora salienta que não basta que os corpos sejam cuidados para torná-los mais hábeis, mas é preciso poder governá-los.

É importante ressaltar ainda que, como coloca Foucault (2004), as relações de poder não são más em si mesmas, constituindo-se como algo do que seria preciso se libertar. É preciso compreender que, na me- dida em que não é possível existir sociedades sem relações de poder, o problema não seria tentar dissolvê-las na utopia de uma comunicação totalmente transparente, mas buscar, através da ética e da prática de si, possibilidades de, nos jogos de poder, jogar com um mínimo de dominação possível.

Não se trata, assim, de julgar se os discursos sobre a formação em saúde são verdadeiros ou falsos, mas mediante o exercício genealógico compreender como tais discursos foram legitimados, adquirindo estatuto de verdade. Na medida em que a formação profissional em saúde é entendida como um campo de produção de sujeitos, pode-se afirmar que, ao mesmo tempo em que a mesma opera no governamento das condutas dos sujeitos aos quais se destina, sempre é possível pensar em formas de resistência e na criação de outros modos de existência.

\section{Referências}

Bernardes, Anita Guazzelli. (2006). Políticas da Existência no Campo da Saúde: o público como um dispositivo. Tese de Doutorado. Pontifícia Universidade Católica do Rio Grande do Sul, Porto Alegre. Disponível em: http:// tede.pucrs.br/tde arquivos/20/ TDE-2007-03-08T053803Z-400/ Publico/387792.pdf. Acesso em: 08 de agosto de 2012. 
Bernardes, Anita Guazzelli; Morais, Gisbelle; Oliveira Junior, Luiz Barbosa. (2009). Políticas de Saúde: Alteridade e questão indígena. Em Silva, Mozart Linhares da; Hillesheim, Betina; Oliveira, Cláudio José de. (Orgs.). Estudos Culturais, Educação e Alteridade (pp. 108-133). $1^{\mathrm{a}}$ ed. Santa Cruz do Sul: EDUNISC.

Bernardes, Anita Guazzelli; Quinhones, Dionatas Godoy. (2009). Práticas de cuidado e produção de saúde: Formas de governamentalidade e alteridade. Psico, Porto Alegre, PUCRS, 40 (2), pp. 153-161, abr./jun. Disponível em: $\quad$ http://revistaseletronicas. pucrs.br/ojs/index.php/revistapsicol article/viewFile/5743/4527. Acesso em: 10 de agosto de 2011.

Bernardes, Anita Guazzelli; Hillesheim, Betina. (2012). Insistência em minorar: reflexões sobre políticas públicas e saúde. Avances en Psicología Latinoamericana, Bogotá (Colombia), 30(2), pp. 365-376.

Brasil. (1988). Constituição da República Federativa do Brasil. Brasília, DF: Senado Federal.

Brasil. (1990). Lei $n^{\circ} 8.080$ de 19 de setembro de 1990. Dispõe sobre as condições para a promoção, proteção e recuperação da saúde, a organização e o funcionamento dos serviços correspondentes e dá outras providências.

Brasil. Ministério da Saúde. Gabinete do Ministro. (2004a). Portaria $N^{o}$ 198/GM/MS de 13 de fevereiro de 2004. Institui a Política Nacional de Educação Permanente em Saúde como estratégia do Sistema Único de Saúde para a formação e o desenvolvimento de trabalhadores para o setor e dá outras providências. Disponível em: http://portal. saude.gov.br/portal/arquivos/pdf/ portariagm198polos.pdf Acesso em: 08 de dezembro de 2013.

Brasil. Ministério da Saúde. Secretaria de Gestão do Trabalho e da Educação na Saúde. Departamento de Gestão da Educação na Saúde. (2004b). Política de educação e desenvolvimento para o SUS: caminhos para a educação permanente em saúde: pólos de educação permanente em saúde. Série C. Projetos, Programas e Relatórios. Brasília, DF.

Carvalho, Yara Maria de; Ceccim, Ricardo Burg. (2009). Formação e Educação em Saúde: aprendizados com a Saúde Coletiva. Em CAMPOS, Gastão Wagner de Sousa et al (Orgs.). Tratado de Saúde Coletiva (pp.137170). São Paulo-Rio de Janeiro: Hucitec-Fiocruz. 
Ceccim, Ricardo Burg. (2005). Educação Permanente em Saúde: desafio ambicioso e necessário. Interface - Comunicação, Saúde, Educação, v.9, n.16, p.161-168, setembro 2004/fevereiro. Disponível em: http://www.escoladesaude.pr.gov. br/arquivos/File/textos\%20eps/ educacaopermanente.pdf. Acesso em: 07 de maio de 2011.

Davini, Maria Cristina. (2009). Enfoques, Problemas e Perspectivas na Educação Permanente dos Recursos Humanos de Saúde. Em BRASIL. Ministério da Saúde. Secretaria de Gestão do Trabalho e da Educação na Saúde. Departamento de Gestão da Educação em Saúde. Política Nacional de Educação Permanente em Saúde (pp.39-58). Brasília: Ministério da Saúde.

Duarte, André. (2009). Foucault e as novas figuras da biopolítica: o fascismo contemporâneo. Em Veiga-Neto, Alfredo; Rago, Margareth. (Orgs). Para uma vida não-fascista (pp. 35-50). Belo Horizonte: Autêntica Editora.

Foucault, Michel. (1997). Resumo dos Cursos do Collège de France. Rio de Janeiro: Jorge Zahar Editor.
Foucault, Michel. (1999). Em defesa da sociedade. São Paulo: Martins Fontes.

Foucault, Michel. (2003). Ditos e escritos IV: estratégia, poder-saber. Rio de Janeiro: Forense Universitária.

Foucault, Michel. (2004). A Arqueologia do Saber. $7^{\mathrm{a}}$ ed. Rio de Janeiro: Forense Universitária.

Foucault, Michel. (2005). História da Sexualidade I: a vontade de saber. $16^{\mathrm{a}}$ ed. Rio de Janeiro: Edições Graal.

Foucault, Michel. (2007). Microfísica do Poder. 24 ${ }^{\mathrm{a}}$ ed. Rio de Janeiro: Graal. Foucault, Michel. (2008). Segurança, Território, População. São Paulo: Martins Fontes.

Fimyar, Olena. (2009). Governamentalidade como ferramenta conceitual na pesquisa de políticas educacionais. Revista Educação e Realidade 34(2): 35-56,mai/ago.Disponívelem: $\underline{\text { http:// }}$ seer.ufrgs.br/educacaoerealidadel article/view/8308. Acesso em 12 de julho de 2013.

Haddad, Jorge; Roschke, Maria Alice Clasen; Davini, Maria Cristina. (1994). Educación permanente de personal de salud. Serie desarrollo de recursos humanos en salud. Washington, D.C.: OPS. 
Lazzarato, Maurizio. (2008). Biopolítica/ Bioeconomia. Em Passos, Izabel C. F. Poder, normalização e violência: incursões foucaultianas para a atualidade (pp. 41-42). Belo Horizonte: Autêntica.

Merhy, Emerson Elias. (2005). Saúde: a cartografia do trabalho vivo. $2^{\mathrm{a}}$ ed. São Paulo: Hucitec.

Nardi, Henrique Caetano; Tittoni, Jaqueline; Giannechini, Letícia; Ramminger, Tatiana. (2005). Fragmentos de uma genealogia do trabalho em saúde: a genealogia como ferramenta de pesquisa. Cad. Saúde Pública, Rio de Janeiro, 21(4):1045-1054, julago. Disponível em: http://www. scielo.br/scielo.php? script $=$ sci arttext\&pid=SO102$\underline{311 \times 2005000400007}$. Acesso em: 18 de julho de 2013.

Nardi, Henrique Caetano; Silva, Rosane Neves da. (2005). Ética e subjetivação: as técnicas de si e os jogos de verdade contemporâneos. Em Guareschi, N.M.F.; Hüning, S.M. (org.). Foucault e a Psicologia (pp. 93-106). Porto Alegre: ABRAPSO SUL.

Nunes, Everardo Duarte. (2009). Saúde Coletiva: história recente, passado antigo. Em Campos, Gastão Wagner de Sousa et al (Orgs.). Tratado de
Saúde Coletiva (pp. 19-39). São Paulo-Rio de Janeiro: HucitecFiocruz.

Oksala, Johanna. (2011). Como ler Foucault. Rio de Janeiro: Zahar.

Pagliosa, Fernando Luiz; Da Ros, Marco Aurélio. (2008). O Relatório Flexner: Para o Bem e Para o Mal. Revista Brasileira de Educação Médica. 49232 (4) : 492-499. Disponível em: http://www.scielo.br/pdf/rbem/ v32n4/v32n4a12.pdf. Acesso em: 22 de março de 2011.

Revel, Judith. (2006). Nas origens do biopolítico: de Vigiar e Punir ao pensamento da atualidade. Em Gondra, José; Kohan, Walter. Foucault 80 anos (pp. 51-62). Belo Horizonte: Autêntica.

Saraiva, Karla; Veiga-Neto, Alfredo. (2009). Modernidade Líquida, Capitalismo Cognitivo e Educação Contemporânea. Revista Educação e Realidade. 34(2):187-201 mai/ago.

Disponível em: http://seer.ufrgs. br/educacaoerealidadelarticlel view/8300/55. Acesso em 10 de julho de 2013.

Gisele Santin: Graduada em Psicologia e Mestre em Educação pela Universidade de Santa Cruz do Sul (UNISC). Docente do Departamento de Psicologia da Univer- 
sidade de Santa Cruz do Sul. Psicóloga no Centro de Atenção Psicossocial da cidade de Encantado e Coordenadora Municipal de Saúde Mental

E-mail: gissantin@yahoo.com.br

Betina Hillesheim: Doutora em Psicologia (PUCRS), docente e pesquisadora do depar- tamento de Psicologia e do Programa em Pós-Graduação em Educação da Universidade de Santa Cruz do Sul (UNISC)

E-mail: betinah@unisc.br

Recebido em: 03/11/2013 - Aceito em: 17/01/2014 